\title{
A CLINICAL AND HISTOPATHOLOGICAL STUDY OF LICHEN PLANUS
}

\author{
Ch. Madhu Babu1, P. Padmaja², M. Roopa Shree 3
}

1 Professor, Department of Dermatology, Venereology, and Leprology, Osmania Medical College and General Hospital. ${ }^{2}$ Associate Professor, Department of Dermatology, Venereology, and Leprology, Osmania Medical College and General Hospital. 3JuniorResident, Department of Dermatology, Venereology, and Leprology, Osmania Medical College and General Hospital.

ABSTRACT
BACKGROUND
Lichen planus is an idiopathic subacute or chronic inflammatory disease of the skin, mucous membranes, and nails. We studied
the clinicopathological profile of 50 cases of Lichen planus in Osmania General Hospital from September 2010-April 2012.

\section{METHODS}

A total of 50 cases Lichen planus attending DVL OPD at OGH were studied. Clinical features like age, sex, type of Lichen planus, location were recorded in the case record form. Histological features of Lichen planus were studied.

\section{RESULTS}

Out of 50 cases, majority (46\%) were of Generalised Lichen Planus. Majority of cases were in the age group of 20-40 years and showed Male preponderance. Most commonly, violaceous lesions occurred in Lichen planus pigmented in Lichen planus pigmentosus and both violaceous and pigmented in Lichen planopilaris.

\section{CONCLUSIONS}

Among the various types of Lichen Planus, Generalised Lichen Planus is the commonest (46\%). Other clinical variants like Hypertrophic, Mucosal (Oral and genital), Linear, Actinic, Lichen Planus Pigmentosus, Follicular, Palmoplantar, and Vesiculobullous were seen less commonly. Most of the components of Lichen Planus on histopathology exhibit apoptosis of individual cells with formation of colloid bodies, hydropic degeneration of basal cells, melanin incontinence, and band-like inflammatory infiltrate at the dermoepidermal junction.

\section{KEYWORDS}

Lichen Planus, Clinico-histopathological.

HOW TO CITE THIS ARTICLE: Babu CM, Padmaja P, Shree MR. A clinical and histopathological study of lichen planus. J.Evolution Med. Dent. Sci. 2016;5(55):3790-3795, DOI: 10.14260/jemds/2016/868

\section{INTRODUCTION}

Lichen planus was first described in 1869 by Erasmus Wilson. The primary lesion were papules and had a resemblance to the Lichen fungi on trees.[1]It is an idiopathic, subacute, or chronic inflammatory disease of the skin characterized by pruritic, purple, plane topped, polygonal papule that affects skin, mucous membranes, hair follicles, and nails.[2] Exact pathogenesis of Lichen planus is still unclear. Several hypotheses have been made regarding its aetiology including genetic, infective, psychogenic, and autoimmune factors (Sugerman et al[3] Sontheimer, 2009.[4]) Recent studies provide evidence that autoreactive cytotoxic $\mathrm{T}$ lymphocytes are the effector cells, which cause degeneration and destruction of keratinocytes causing keratinocyte apoptosis (Sontheimer, 2009.[4]). The lesions may result in longstanding residual hyperpigmentation especially in dark skinned patients. The slightly scaly surface is typically crossed by delicate white lines known as Wickham's striae.

Financial or Other, Competing Interest: None.

Submission 21-04-2016, Peer Review 02-06-2016,

Acceptance 09-06-2016, Published 11-07-2016.

Corresponding Author:

Dr. Ch. Madhu Babu,

Flat No: 202, Lakshmi Nivas,

RTC Colony,

Champapet

Hyderabad-500079.

E-mail:drchmadhubabu@gmail.com

DOI: $10.14260 /$ jemds $/ 2016 / 868$
LP has characteristic clinical and histopathological features, which make the diagnosis relatively easy. The following are the clinical variants of LP.

1. Based on Configuration: Annular and Linear LP

2. Based on Morphology: Hypertrophic, Atrophic, Vesiculobullous, Erosive/ulcerative, Follicular, Linear, Lichen Planus Pigmentosus, Eruptive-Guttate.

3. Site of Involvement: Generalised, Palms and Soles, Mucous Membranes, Nails, Scalp.

4. Special Forms: Actinic LP, Lichen planus Pemphigoides.

\section{CLINICAL FEATURES}

Most cases of lichen planus (LP) are insidious. Lesions usually develop on flexural surfaces of the limbs, such as the wrists. After a week or more, a generalized eruption develops with maximal spreading within 2-16 weeks. Pruritus is common in Lichen planus, but varies in severity depending on the type of lesion and the extent of involvement. Hypertrophic lesions are extremely pruritic.

Oral lesions may be asymptomatic or have a burning sensation or they may even be painful if erosions are present. In more than $50 \%$ of patients with cutaneous disease, the lesions resolve within 6 months and $85 \%$ of cases subside within 18 months. On the other hand, oral Lichen planus had been reported to have a mean duration of 5 years. Large, annular, hypertrophic lesions, and mucous membrane involvement are more likely to become chronic. 
In addition to the cutaneous eruption, Lichen Planus (LP) can involve the mucous membranes, the genitalia, the nails, and the scalp. The clinical presentation of Lichen planus has several forms: actinic (In sun-exposed areas), annular, atrophic, erosive, follicular, hypertrophic, linear, pigmented, and vesicular/bullous. The papules are violaceous, shiny, and polygonal; varying in size from $1 \mathrm{~mm}$ to greater than $1 \mathrm{~cm}$ in diameter (See the image below). They can be discrete or arranged in groups of lines or circles. Characteristic fine white lines called Wickham striae are often found on the papules.

Mucous membrane involvement is common and maybe found in patients who do not have skin involvement. Lesions are most commonly found on the tongue and the buccal mucosa; they are characterized by white or gray streaks forming a linear or reticular pattern on a violaceous background. Oral lesions are classified as reticular, plaque like, atrophic, papular, erosive, and bullous. Ulcerated oral lesions may have a higher incidence of malignant transformation in men, but this observation maybe confounded by other factors such as smoking and chewing tobacco. Lesions may also be found on the conjunctivae, the larynx, the oesophagus, the tonsils, the tympanic membrane, the bladder, the vulva, and the vaginal vault; throughout the gastrointestinal tract; and around the anus.

Genital involvement is common in Lichen planus. Typically, men develop annular lesions on the glans. Wickham striae may also be observed on these lesions. Vulvar involvement can range from reticulate papules to severe erosions. Dyspareunia, a burning sensation, and pruritus are common in women. Vulvar and urethral stenosis may be a complication. It is estimated that more than $50 \%$ of women with oral lichen planus also had undiagnosed vulvar Lichen planus.

Nail findings are found in roughly $10 \%$ of patients with Lichen planus. These findings are most commonly longitudinal grooving and ridging. Hyperpigmentation, subungual hyperkeratosis, onycholysis, and longitudinal melanonychia can result from Lichen planus. Rarely, inflammation may result in permanent destruction of the nail matrix with subsequent pterygium formation. Lichen planus has been linked to childhood idiopathic nail atrophy and may overlap with twenty-nail dystrophy of childhood.

Cutaneous lesions may be accompanied by follicular and perifollicular lesions on the scalp, which maybe violaceous, scaly, and pruritic papules. These lesions can progress to atrophic cicatricial alopecia known as Lichen planopilaris. This can appear even many weeks after the skin lesions have disappeared. Pseudopelade can be a final endpoint.

\section{Variations in Lichen Planus include the following}

- Hypertrophic Lichen Planus: These extremely pruritic lesions are most often found on the extensor surfaces of the lower extremities especially around the ankles. Hypertrophic lesions are often chronic; residual pigmentation and scarring can occur when the lesions eventually clear.

- Atrophic Lichen Planus: Atrophic Lichen planus is characterized by a few lesions, which are often the resolution of annular or hypertrophic lesions.
- Erosive/Ulcerative Lichen Planus: These lesions are found on the mucosal surfaces and evolve from sites of previous Lichen planus involvement.

- Follicular Lichen Planus (Aka Lichen Planopilaris): This is characterized by keratotic papules that may coalesce into plaques. This condition is more common in women than in men and ungual and erosive mucosal involvement is more likely to be present. A scarring alopecia may result.

- Annular Lichen Planus: Lichen planus papules that are purely annular are rare. Annular lesions with an atrophic centre can be found on the buccal mucosa and the male genitalia.

- Linear Lichen Planus: Isolated linear lesions may form a Zosteriform lesion or they may develop as a Koebner effect.

- Vesicular and Bullous Lichen Planus: Most commonly, these lesions develop on the lower limbs or in the mouth from pre-existing Lichen planus lesions. A rare condition, Lichen planus pemphigoides, is a combination of both Lichen planus and bullous pemphigoid.

- Actinic Lichen Planus: Subtropic or actinic Lichen planus occurs in regions, such as Africa, the Middle East, and India. This mildly pruritic eruption usually spares the nails, the scalp, the mucous membranes, and covered areas. Lesions are characterized by nummular patches with a hypopigmented zone surrounding a hyperpigmented centre.

- Lichen Planus Pigmentosus: This is a rare variant of Lichen planus, but can be more common in persons with darker-pigmented skin such as Latinos or Asians. It usually appears on face and neck. Some believe it is similar to or the same as erythema dyschromicum perstans (i.e., Ashy dermatosis).

- Lichen Planus Pemphigoides: This is a rare form of Lichen planus. Blisters subsequently develop on Lichen planus lesions. Clinically, histopathologically, and immunopathologically, it has features of Lichen planus and bullous pemphigoid, but it carries a better prognosis than pemphigoid.

\section{Differential Diagnosis}

- Dermatological manifestations of graft vs host disease.

- Guttate psoriasis.

- Lichen nitidus.

- Lichen simplex chronicus.

- Paediatric syphilis.

- Pityriasis rosea.

- Plaque psoriasis.

- Tinea corporis.

\section{MANAGEMENT}

\section{Diagnostic Workup}

- Laboratory Studies: Direct immunofluorescence study in Lichen Planus (LP) reveals globular deposits of immunoglobulin $\mathrm{M}$ (IgM) and complement mixed with apoptotic keratinocytes.

- Histopathological Examination: Typical papules of Lichen planus show the following features on histopathology. 


\section{Epidermal Changes}

Compact orthokeratosis, wedge-shaped hypergranulosis, irregular acanthosis, colloid bodies, flattened rete ridges, liquefactive degeneration of basal layer, and Max Joseph's space.

\section{Dermal Changes}

Band-like infiltrate hugging the basal layer, perifollicular infiltrate, lymphocytes, plasma cells, eosinophils, and melanin incontinence.

\section{TREATMENT}

\section{Medical Care}

Lichen planus (LP) is a self-limited disease that usually resolves within 8-12 months. Mild cases can be treated with fluorinated topical steroids. More severe cases, especially those with scalp, nail, and mucous membrane involvement may need more intensive therapy.

\section{Medical Treatment}

The first-line treatments of cutaneous Lichen planus are topical steroids particularly class I or II ointments. A second choice would be systemic steroids for symptom control and possibly more rapid resolution. Many practitioners prefer intramuscular triamcinolone 40-80 mg every 6-8 weeks. Oral metronidazole has been shown to be an effective therapy for some patients.[5]Oral acitretin has been shown to be effective in published studies.[6]Many other treatments including mycophenolate mofetil at 1-1.5 g twice daily are of uncertain efficacy owing to the paucity of experience. In a randomised double-blinded study, sulfasalazine at up to $2.5 \mathrm{~g}$ /day for 6 weeks showed improvement in lesions $(>80 \%)$ and pruritus $(>90 \%)$ in patients with generalized Lichen planus.

For Lichen planus of the oral mucosa, topical steroids are usually tried first. Topical and systemic cyclosporine have been tried with some success.[7], however, a randomised double-blind study indicated that topical cyclosporine was a less effective, but much more costly regimen than clobetasol.[8]Newer topical calcineurin inhibitors have replaced topical cyclosporine for the treatment of Lichen planus. Other options include oral or topical retinoids. Even with these effective treatments, relapses are common.

Close monitoring of lipid levels is suggested for patients with Lichen planus who are treated with oral retinoid agents because a case control study found that the risk of dyslipidaemia in these patients is increased 2-3 fold.[9] In fact, according to a meta-analysis of 5,242 patients even those who did not receive retinoids might still have dyslipidaemia.

Patients with widespread Lichen planus may respond to narrow-band or broadband UV-B therapy.[10] Psoralen with UV-A (PUVA) therapy for 8 weeks has been reported to be effective. Risks and benefits of this treatment should be considered. PUVA is carcinogenic. Long-term risks include dose-related actinic degeneration, squamous cell carcinoma, and cataracts. A phototoxic reaction with erythema, pruritus, phytophotodermatitis, and friction blisters could occur.

UV-A therapy combined with oral psoralen consists of oral psoralen $(0.6 \mathrm{mg} / \mathrm{kg}), 1.5-2$ hours before ultraviolet light, which usually starts at $0.5-1 \mathrm{~J} / \mathrm{cm}^{2}$ and is increased by 0.5 $\mathrm{J} / \mathrm{cm}^{2}$ per visit. Use of topical ointment at the time of receiving UV-A treatment may decrease the effectiveness of PUVA. Precaution should be taken for persons with a history of skin cancers or hepatic insufficiency. Apremilast may be an effective treatment for Lichen planus, but double-blinded controlled trials are lacking. ${ }^{[11]}$

\section{Complications}

Malignant transformation has been reported in ulcerative Oral Lichen Planus (OLP).[12]Cutaneous hypertrophic lichen planus resulting in Squamous Cell Carcinoma (SCC) was reported in a series of 38 patients.[13]Pruritic and painful vulvar lichen planus has been a precursor to SCC in a small number of cases.

Infection, osteoporosis, adrenal insufficiency, bone marrow suppression, renal damage, hyperlipidemia, and growth restriction in children may occur due to medication adverse effects. Post inflammatory/residual hyperpigmentation may be a common marker after Lichen planus has subsided. Alopecia associated with Lichen planus is often permanent.

Hepatitis C virus infection may be present in $16 \%$ of Lichen planus patients. Additionally, a meta-analysis reported that hepatitis $C$ virus seropositivity could be 6 times higher in oral Lichen planus patients than controls.[14]

\section{Prognosis}

The prognosis for Lichen planus is good as most cases regress within 18 months. Some cases recur. In Lichen planus, atrophy and scarring are seen in hypertrophic lesions and in lesions on the scalp. Cutaneous Lichen planus does not carry a risk of skin cancer, but ulcerative lesions in the mouth, particularly in men, do have a low rate of malignant transformation. However, the malignant transformation rate of oral Lichen planus is low $(<2 \%$ in one report). Vulvar lesions in women may also be associated with squamous cell carcinoma.

\section{Patient Education}

Patients should be told about the self-limiting nature of Lichen planus. Because Lichen planus is not common, no large, randomised, controlled clinical trials have been conducted for therapy. Several treatments may need to be tried.

Patients should be told about the small likelihood of recurrence and the potential adverse effects from the various treatments offered.

Cutaneous LP has worldwide distribution with its incidence varying from $0.22 \%$ to $1 \%$ depending upon geographic location (Boyd and Neldner, 1991).[15] According to one study, LP represents $0.38 \%$ of all dermatology outpatients in India (Bhattacharya et al., 2000).[16] However, there is a paucity of Indian literature describing the clinicopathological profile of Lichen planus. Therefore, we conducted this study to document and analyse the clinicopathological profile of LP in Indian population.

\section{MATERIALS AND METHODS}

The study was conducted in the DVL Department, Osmania General Hospital from September 2010-April 2012. Retrospectively, we analysed all the cases of Lichen planus received in our department. A total of 50 clinically diagnosed Lichen planus cases were included for studying the clinical and histopathological aspects of Lichen planus. Clinical features like age, sex, duration of the lesion, type of Lichen planus, significant family history and personal history, history of associated diseases, and drug intake was taken and entered 
in the proforma. After detailed general and local examination, the site of biopsy was selected. The selected patients consent was taken after explaining the details of biopsy procedure.

The biopsy is done on the lesion along with the surrounding area with a $4 \mathrm{~mm}$ punch biopsy specimens are stained with $\mathrm{H}$ and $\mathrm{E}$ and the histopathological features of Lichen planus were studied under a microscope. Each skin biopsy was subjected to systematic, critical interpretive assessments in sequence of epidermal changes like basal cell death or vacuolar change, varying thickness of different layers of epidermis. Decimal changes like interface dermatitis and composition of different cell types, focal or diffuse nature of the lesion, pigment incontinence along with appendageal involvement were noted. All these features were noted for comparison with clinical subtype.

\section{Statistical Analysis}

Fisher's exact test was used to assess associations between various variables. All analyses were performed using SPSS software. A p-value of less than 0.05 was considered statistically significant.

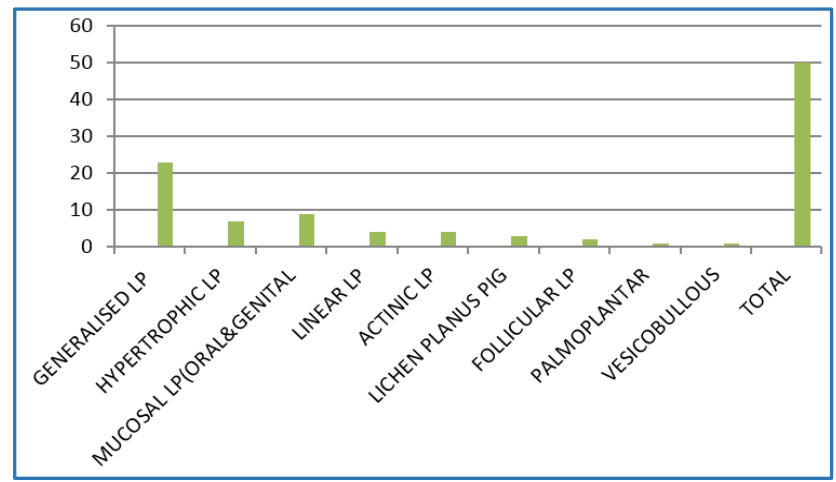

Graph-1: Distribution of Cases

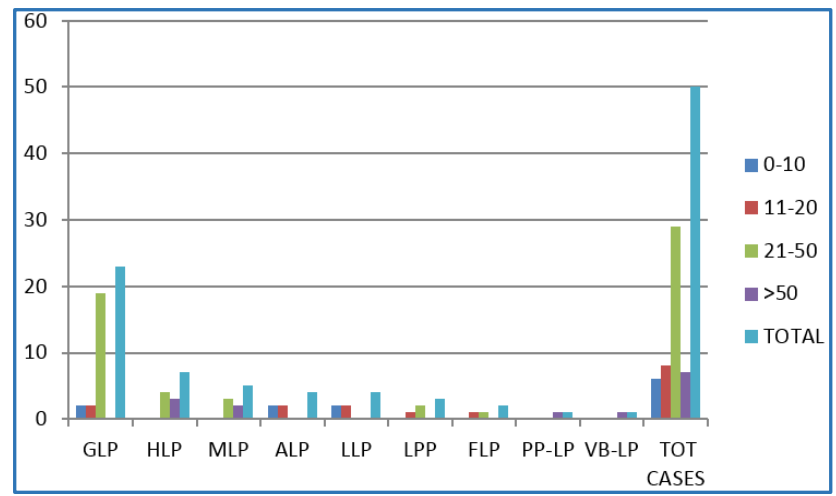

Graph-2: Age Distribution (In Years) of the Individual Cases

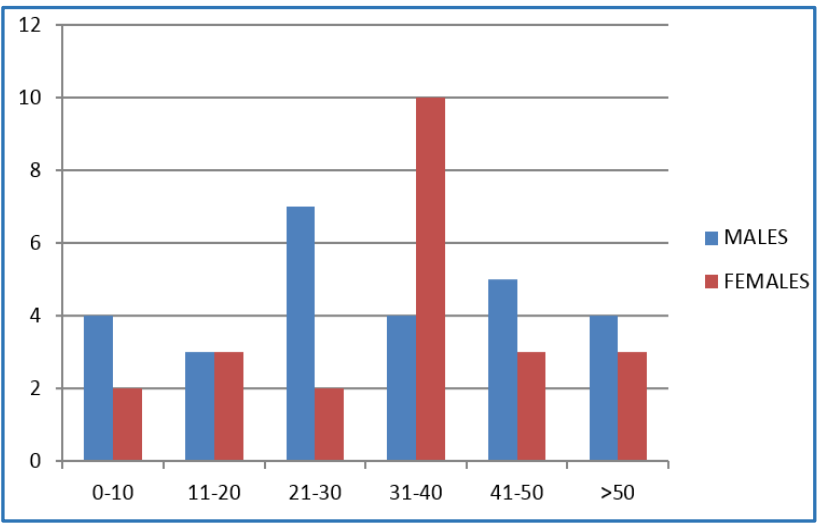

Graph-3: Age and Sex Distribution

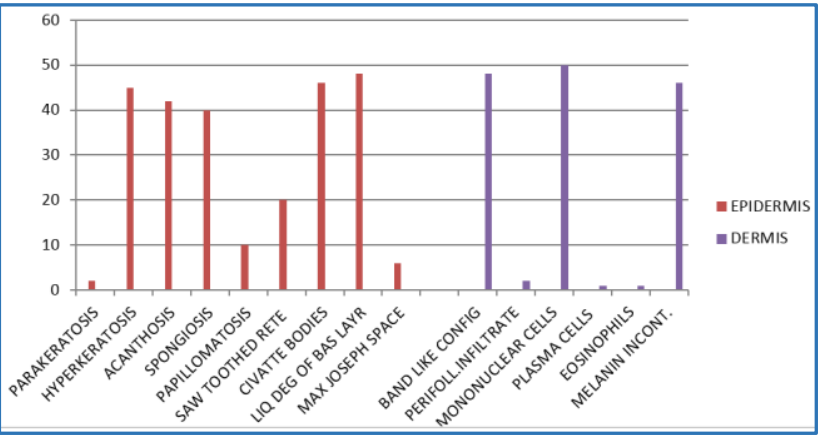

Graph-4: Histopathological Findings-Epidermal and Dermal

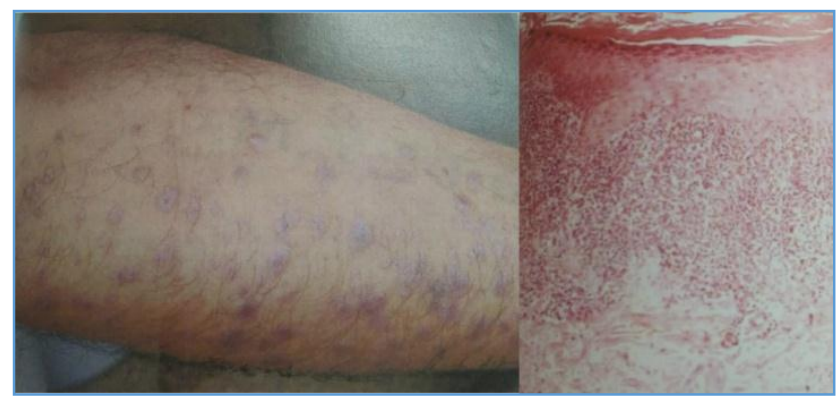

Picture-1: (Clinical and Histopathological Correlation)

Lichen planus - Flat topped violaceous papules with fine scale clinically and histopathology showing hyperkeratosis, irregular acanthosis, and band-like inflammatory cells.

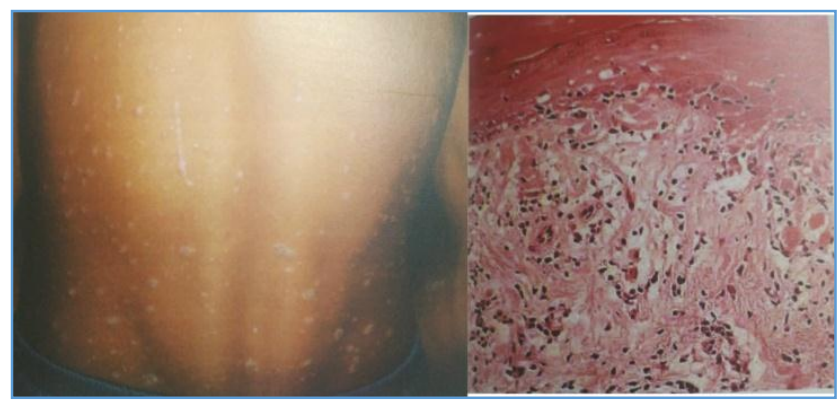

Picture-2: (Clinical and Histopathological Correlation)

Lichen planus - Generalised with Koebner's phenomenon, histopathology showing basal degeneration and civatte bodies. 


\section{RESULTS}

Out of 50 cases of Lichen planus studied, 23 (46\%) cases were of generalised Lichen planus, 7 (14\%) cases were of hypertrophic LP, 5 (10\%) cases were of mucosal LP (Oral+genital), 4 (8\%) cases were Actinic LP and Linear LP each. $3(6 \%)$ cases were Lichen planus pigmentosus. 2 (4\%) cases were Follicular LP. 1 (2\%) case was palmoplantar and vesiculobullous type each. Out of 50 cases, 47 (94\%) cases were clinically diagnosed and histopathologically confirmed. $3(6 \%)$ cases were clinically doubtful and confirmed histologically. 27/50 (54\%) were males and 23/50 (46\%) were females with sex ratio of 1.17:1 (Male:female). Majority of the patients of Generalised Lichen Planus, Hypertrophic LP, Mucosal LP, and Follicular LP were in the age group of 21-50 years.

The age range of the patients was from 5 to $>50$ years in males and females. All the cases (50) were divided into different subgroups based on clinical variants, age, and sex and the histopathological findings in epidermis and dermis were noted. In epidermis out of 50 cases, Parakeratosis was seen in 2 cases, Hyperkeratosis in 45 cases, Acanthosis in 42 cases, Spongiosis in 40 cases, Papillomatosis in 10 cases, Sawtoothed rete ridges in 20 cases, Civatte bodies in 46 cases, Liquefactive degeneration of basal layer in 48 cases, and MaxJoseph's space was seen in 6 cases. In dermis out of 50 cases, band-like configuration hugging the basal layer was seen in 48 cases, perifollicular infiltrate in 2 cases, mononuclear cells in all the 50 cases, plasma cells and eosinophils each in 1 case and melanin incontinence was seen in 46 cases.

\section{DISCUSSION}

This prospective study is done to assess the different types of Lichen planus, which were confirmed histopathologically. In our study, Generalised Lichen Planus was the most common type of LP. It was about 46\%. Hypertrophic Lichen Planus was the next most common type accounting for $14 \%$ of cases. Mucosal Lichen Planus was seen in $10 \%$ of our cases with oral mucosal involvement in $8 \%$ of cases and genital mucosal involvement in $2 \%$ of cases. Next common variant in our study was Linear Lichen Planus and Actinic Lichen Planus both accounting for $8 \%$ each. Lichen Planus Pigmentosus was seen in $6 \%$ cases in our study. Follicular Lichen Planus was seen in $4 \%$ of cases, palmoplantar and vesiculobullous variants were seen $2 \%$ each in our study. Singh OP and Kanwar AJ (1976) ${ }^{[17]}$ found the incidence of various lesions clinically in North India as follows in comparison with our study.

\begin{tabular}{|c|c|c|}
\hline $\begin{array}{c}\text { Type } \\
\text { of } \\
\text { Lesion }\end{array}$ & $\begin{array}{c}\text { Present } \\
\text { Study } \\
\mathbf{\%}\end{array}$ & $\begin{array}{c}\text { Singh 0P and } \\
\text { Kanwar AJ } \\
\text { Study \% }\end{array}$ \\
\hline Generalised LP & 46 & 74.6 \\
\hline Hypertrophic LP & 14 & 12.7 \\
\hline Actinic LP & 8 & 7.48 \\
\hline LP pigmentosus & 6 & 1.8 \\
\hline LP pemphigoides & 0 & 1.6 \\
\hline \multicolumn{3}{|c|}{ Table 1 } \\
\hline
\end{tabular}

Sehgal and Rege in Goa[18] studied 147 patients and found the incidence of Lichen planus clinically in the following order.

\begin{tabular}{|c|c|c|}
\hline $\begin{array}{c}\text { Type } \\
\text { of } \\
\text { Lesion }\end{array}$ & $\begin{array}{c}\text { Present } \\
\text { Study } \\
\text { \% }\end{array}$ & $\begin{array}{c}\text { Sehgal and } \\
\text { Rege Study } \\
\text { \% }\end{array}$ \\
\hline Generalised LP & 46 & 75 \\
\hline Hypertrophic LP & 14 & 15.5 \\
\hline LP pemphigoides & 0 & 2.3 \\
\hline LP Planopilaris & 4 & 1.5 \\
\hline \multicolumn{2}{|c|}{ Table 2} \\
\hline
\end{tabular}

Coming to histopathological analysis in our study, the epidermal changes most evident in many cases were hyperkeratosis, acanthosis, civatte bodies, and liquefactive degeneration. Dermal changes most evident in many cases were band-like configuration, hugging basal layer, and the inflammatory cells were lymphocytes in all cases. Very few cases showed plasma cells and eosinophils. Pigment incontinence was very predominant in Actinic Lichen Planus. Epidermal hypertrophy was markedly seen in Hypertrophic variant.

In 1965, Ellis Francis.[19] did analysis of one hundred biopsies and recorded almost similar findings histopathologically.

\section{Changes in EPIDERMIS are as follow}

\begin{tabular}{|c|c|c|c|}
\hline $\begin{array}{c}\text { Sl. } \\
\text { No. }\end{array}$ & Features & $\begin{array}{c}\text { Present } \\
\text { Study } \\
\text { \% }\end{array}$ & $\begin{array}{c}\text { Ellis Francis } \\
\text { (1965) Study } \\
\text { \% }\end{array}$ \\
\hline 1 & Parakeratosis & 5 & 12 \\
\hline 2 & Acanthosis & 73.3 & 23 \\
\hline 3 & Atrophy & 8.3 & 47 \\
\hline 4 & Civatte bodies & 0.8 & 37 \\
\hline 5 & Liq. degeneration & 83.3 & 100 \\
\hline 6 & $\begin{array}{c}\text { Max-Joseph } \\
\text { space }\end{array}$ & 13.3 & 17 \\
\hline 7 & Follicular lesion & 5 & 6 \\
\hline & \multicolumn{3}{|c|}{ Table 3 } \\
\hline
\end{tabular}

\section{Changes in DERMIS are as follows}

\begin{tabular}{|c|c|c|c|}
\hline $\begin{array}{c}\text { Sl. } \\
\text { No. }\end{array}$ & Features & $\begin{array}{c}\text { Present } \\
\text { Study } \\
\text { \% }\end{array}$ & $\begin{array}{c}\text { Ellis Francis } \\
\text { (1965) Study } \\
\text { \% }\end{array}$ \\
\hline 1 & $\begin{array}{c}\text { Band-like infiltrate } \\
\text { hugging basal layer }\end{array}$ & 96.6 & 100 \\
\hline 2 & Mostly lymphocytes & 100 & 100 \\
\hline 3 & Plasma cells & 3.3 & 3 \\
\hline 4 & Eosinophils & 3.3 & 0 \\
\hline \multicolumn{3}{|c|}{ Table 4 } \\
\hline
\end{tabular}

\section{CONCLUSION}

In conclusion, our results indicate that among various types of Lichen planus, classical Generalised Lichen Planus is the commonest. Mucosal lesions in these cases were not seen in all cases. Other clinical variants like Hypertrophic, Mucosal (Oral and genital), Linear, Actinic, Lichen Planus Pigmentosus, Follicular, Palmoplantar, and Vesiculobullous Lichen Planus were seen less commonly.

The tie to pathological changes encompassed epidermal basal cell damage seen as apoptosis of individual cells with formation of colloid bodies, hydropic degeneration of the basal cells, melanin incontinence secondary to basal cell 
damage, and band-like inflammatory infiltration hugs the dermo-epidermal junction.

Most of the components of Lichen planus variants exhibit this reaction except for subtle difference that define the particular variant.

Recognition of these commonly encountered problems depends upon the familiarity of clinical presentation and the diagnosis can be confirmed histopathologically. Accurate diagnosis by histopathology also depends on the available clinical information.

Clinicopathological correlation is the key to providing optimal patient care.

\section{REFERENCES}

1. Aal AH, Aziz A. The lichens. Indian Journal of Dermatology and Venereology 1975;41(2):32-7.

2. Elder DE. Lever's histopathology of the skin. $9^{\text {th }}$ ed. Sonia Toussaint and Hideko Kamino 1997:166.

3. Sugerman PB, Satterwhite K, Bigby M. Autocytotoxic Tcell clones in Lichen planus. $\mathrm{Br} J$ Dermatol 2000;142(3):449-56.

4. Sontheimer RD. Lichenoid tissue reaction/interface dermatitis: clinical and histological perspectives. J Invest Dermatol 2009;129(5):1088-99.

5. Rasi A, Behzadi AH, Davoudi S, et al. Efficacy of oral metronidazole in treatment of cutaneous and mucosal Lichen planus. J Drugs Dermatol 2010;9(10):1186-90.

6. Cribier B, Frances C, Chosidow O. Treatment of Lichen planus. An evidence-based medicine analysis of efficacy. Arch Dermatol 1998;134(12):1521-30.

7. Omidian M, Ayoobi A, Mapar MA, et al. Efficacy of sulfasalazine in the treatment of generalized Lichen planus: randomized double-blinded clinical trial on 52 patients. J Eur Acad Dermatol Venereol 2010;24(9): 1051-4.
8. Lim KK, Su WP, Schroeter AL, et al. Cyclosporine in the treatment of dermatologic disease: an update. Mayo Clin Proc 1996;71(12):1182-91.

9. Conrotto D, Carbone M, Carrozzo M, et al. Cyclosporin vs. clobetasol in the topical management of atrophic and erosive oral lichen planus: a double-blind, randomized controlled trial. Br J Dermatol 2006;154(1):139-45.

10. Paul J, Foss CE, Hirano SA, et al. An open-label pilot study of apremilast for the treatment of moderate-to-severe Lichen planus: a case series. J Am Acad Dermatol 2013;68(2):255-61.

11. Arias-Santiago S, Buendia-Eisman A, Aneiros-Fernandez J, et al. Cardiovascular risk factors in patients with lichen planus. Am J Med 2011;124(6):543-8.

12. Pavlotsky F, Nathansohn N, Kriger G, et al. Ultraviolet-B treatment for cutaneous lichen planus: our experience with 50 patients. Photodermatol Photoimmunol Photomed 2008;24(2):83-6.

13. Gonzalez-Moles MA, Scully C, Gil-Montoya JA. Oral Lichen planus: controversies surrounding malignant transformation. Oral Dis 2008;14(3):229-43.

14. Knackstedt TJ, Collins LK, Li Z, et al. Squamous cell carcinoma arising in hypertrophic Lichen planus: a review and analysis of 38 cases. Dermatol Surg 2015;41(12):1411-8.

15. Boyd AS, Neldner KH. Lichen planus. JAM Acad Dermatol 1991;25(4):593-619.

16. Bhattacharya $M$, Kumar B. Lichen planus: a clinical and epidemiological study. J Dermatol 2000;27(9):576-82.

17. Singh OP, Kanwar AJ. Lichen planus in India: an appraisal of 441 cases. Int J Dermat 1976;15(10):752-6.

18. Sehgal VN, Drege V. Lichen planus in India: an appraisal of 147 cases. Ind J Dermat 1974;40(3):104-7.

19. Ellis FA. Histopathology of Lichen planus based on analysis of one hundred biopsy specimen. J Invest dermatol 1967;48:143-8. 